\title{
Preliminary studies investigating the occurrence of Biomphalaria cousini in Brazil
}

\author{
Roberta Lima Caldeira/ ${ }^{+}$, Tatiana Maria Teodoro, Maria Flávia Belfort Gomes, \\ Omar dos Santos Carvalho
}

Laboratório de Helmintologia e Malacologia Médica, Instituto de Pesquisas René Rachou-Fiocruz, Av. Augusto de Lima 1715, 30190-001 Belo Horizonte, MG, Brasil

\begin{abstract}
Specific genetic profiles of Brazilian Biomphalaria species were previously standardized by molecular taxonomy through the analysis of restriction fragments, which were generated by digesting the internal transcribed spacer region of rDNA with the DdeI endonuclease. Biomphalaria amazonica displayed three distinct profiles. To investigate these distinct profiles, the same molecular technique, polymerase chain reaction and restriction fragment length polymorphism, was used with different endonucleases. In addition, morphological data were also used to compare B. amazonica specimens that were collected from Brazil, Colombia and Bolivia. The morphological characters of Bolivian molluscs were similar to $\mathrm{B}$. amazonica, displayed a molecular profile of five restriction fragments and morphological data, whereas the Colombian mollusc population showed morphological characters similar to Biomphalaria cousini and a molecular profile of three restriction fragments, similar to B. cousini. The Brazilian specimens showed the $\mathrm{B}$. amazonica and $\mathrm{B}$. cousini molecular profiles as well as a third profile, which resembled a combination of the Colombian and Bolivian molecular profiles.
\end{abstract}

Key words: Biomphalaria cousin - Biomphalaria amazonica - PCR-RFLP - morphological characters

In Brazil, Biomphalaria glabrata, Biomphalaria tenagophila and Biomphalaria straminea are medically important because they are intermediate hosts of Schistosoma mansoni. Two other species of Biomphalaria, Biomphalaria amazonica and Biomphalaria peregrina also potentially act as potential hosts of the trematode in experimental infection assays that were performed under laboratory conditions (Corrêa \& Paraense 1971, Paraense \& Corrêa 1973). Because B. amazonica and $B$. peregrina may maintain the schistosomiasis life-cycle in both endemic and non-endemic areas, the identification of specific molluscs is crucial. However, the taxonomy of Biomphalaria snails remains unclear due to several difficulties, including the fixation processes for further identification, the small sizes of the specimens and variations in the morphologies of genital organs. As the precise diagnosis of specimens is impaired by the inaccurate identification of morphological characters, molecular techniques have been developed to complement the specific identification of specimens.

Polymerase chain reaction and restriction fragment length polymorphism (PCR-RFLP) analysis have generated data that allow further studies of Biomphalaria molecular taxonomy. Most of the molecular investigations (Carvalho et al. 2001, Caldeira et al. 2004) confirm results from previous research that was based on mor-

Financial support: PAPES V, CNPq-FIOCRUZ

+ Corresponding author: caldeira@cpqrr.fiocruz.br

Received 13 May 2009

Accepted 13 November 2009 phological analyses, which were carried out by Paraense during a 50-year period of Biomphalaria taxonomic classification. Because of the molecular studies, specific molecular profiles were generated and standardized for Brazilian snail species by digesting the internal transcribed spacer region (ITS) of rDNAs with the restriction enzyme DdeI (Vidigal et al. 2000a). Evidence of three molecular profiles was observed for B. amazonica.

To investigate the genetic variation of $B$. amazonica, the present paper employed morphological characterization and PCR-RFLP analysis that targeted the ITS regions of rDNAs with different endonucleases. Snail samples that were previously identified as B. amazonica were obtained from Brazil, Colombia and Bolivia.

DNA samples from Bolivian (Santa Cruz), Colombian (Leticia) and Brazilian [Manaus, state of Amazonas (AM), Barão de Melgaço, state of Mato Grosso (MT), Careiro do Castanho, AM, and Benjamin Constant, AM] specimens that were used for the investigations were obtained from the mollusc collection of the Laboratory of Helminthiasis and Medical Malacology of Instituto de Pesquisa René Rachou-Fiocruz. The PCR-RFLP methodology was performed with the DdeI, AluI, RsaI, HpaII and HaeIII endonucleases following the protocol of Vidigal et al. (2000a).

Of the six endonucleases that cleaved the DNA at specific restriction sites, $D d e \mathrm{I}$ displayed the clearest restriction profiles, as shown herein. Fig. 1 shows the DdeI PCR-RFLP profile with five fragments that was generated from Bolivian snails and Fig. 2 shows the molecular profiles with three fragments that were generated from Colombian samples. Fig. 3 shows three different molecular profiles of Brazilian snails: (i) the profile with three bands corresponds to the profile of the Colombian samples (Lanes 1, 2 from Benjamin Constant, AM; 4 
from Barão de Melgaço, MT and 8, 9 and 13 from Careiro da Várzea, AM), (ii) the profile with five bands is similar to the profiles of the Bolivian specimens (Lane 3 from Benjamin Constant, AM, 10-12 from Careiro da Várzea, AM, and 14-16 from Manaus, AM) and (iii) the profile with nine bands, which is different from the profiles already mentioned, corresponds to the profile of the Brazilian specimens from Barão de Melgaço, MT $(5,6)$ and Careiro da Várzea, AM (7). In the unique profile with nine bands, fragments corresponding to both the Bolivian and Colombian specimens can be detected.

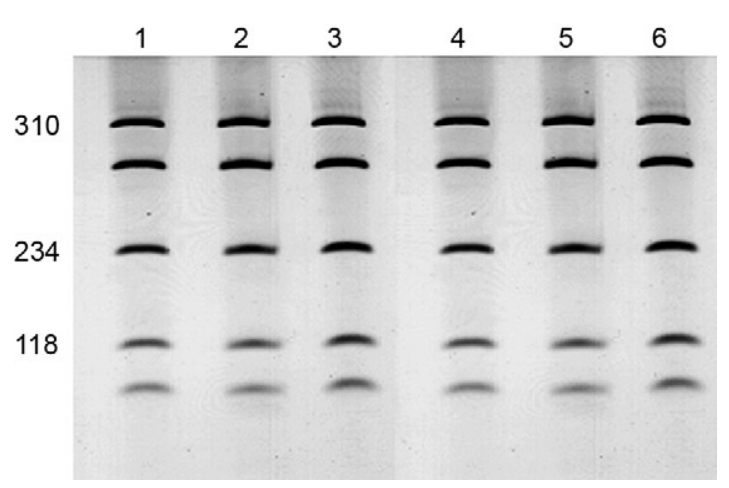

Fig. 1: six percent silver stained polyacrylamide gel showing restriction profiles obtained through of the digested internal transcribed spacer region of DNA ribosomal with DdeI of Biomphalaria snails from Bolivia (Santa Cruz). Molecular size markers are on the left hand side.

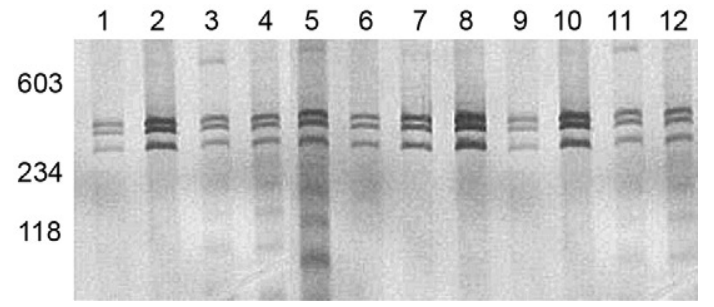

Fig. 2: six percent silver stained polyacrylamide gel showing restriction profiles obtained through of the digested internal transcribed spacer region of DNA ribosomal with DdeI of Biomphalaria snails from Colombia (Leticia). Molecular size markers are on the left hand side.
Interestingly, the morphological characters of the Bolivian specimens correspond to the characters previously described for B. amazonica by Paraense (1966). In contrast, the morphological characters of the Colombian specimens correspond to the characters of Biomphalaria cousini, which were described in the same article. The morphological variations found in the samples analysed in this study are listed in the Table.

Although Paraense (1966) previously described the morphologies of B. amazonica and B. cousini, the author emphasized the difficulties involved in such classifications, which were primarily due to high degrees of similarity between the two species. Likewise, high degrees of similarity between various Biomphalaria species were also described in phylogenetic studies performed by Vidigal et al. (2000b). Those studies demonstrated that the branch with B. amazonica specimens always divided into two clusters that were similar but distinct. One cluster contained specimens from Benjamin Constant, AM and the other cluster contained specimens from Barão de Melgaço, MT. These same specimens were also used in another investigation (Vidigal et al. 2000a) in which the molecular profiles were shown to correspond to the Colombian (Benjamin Constant, AM) and Bolivian profiles (Barão de Melgaço, MT). These results suggest that two different species of Biomphalaria have been incorrectly identified as B. amazonica.

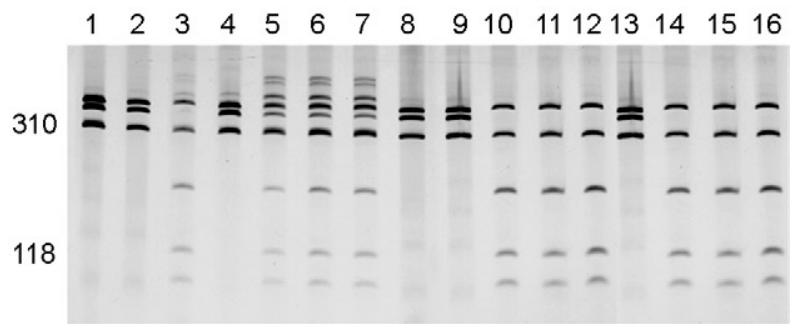

Fig. 3: six percent silver stained polyacrylamide gel showing restriction profiles obtained through of the digested internal transcribed spacer region of DNA ribosomal with DdeI of Biomphalaria snails from Brazil, in the municipalities of Benjamin Constant, state of Amazonas (AM) (Lanes 1-3), Barão de Melgaço, state of Mato Grosso (4-6), Careiro da Várzea, AM (7-13) and Manaus, AM (14-16). Molecular size markers are on the left hand side.

TABLE

Morphological characters of Biomphalaria specimens from Bolivia and Colombia

\begin{tabular}{lcc}
\hline Morphological characters & Specimens from Bolivia & Specimens from Colombia \\
\hline Prostate & Few prostatic diverticula & Many prostatic diverticula \\
& with short ramifications & with ramifications \\
Vagina & Short and vaginal wall & Short and vaginal wall \\
& with a mere elevation \\
Ovotestis & with well-developed and limited pouch & Single, round and short \\
& Single and long & diverticula \\
\hline
\end{tabular}


Most of the specimens exhibiting the molecular profile depicted in Fig. 3 (Lanes 5-7) showed morphological characters corresponding primarily to $B$. amazonica rather than $B$. cousini. Would such a profile be a combination of the B. amazonica and B. cousini profiles?

Due to inaccurate data regarding morphological variations, further studies concerning the molecular taxonomy and phylogenetics of various specimens identified as $B$. amazonica are necessary. Furthermore, $B$. cousini has only been identified in Ecuador and no evidence exists regarding its susceptibility to $S$. mansoni. B. amazonica is a potential host of the trematode. If our hypothesis is correct, a new Biomphalaria species will be added to the Brazilian planorbids fauna.

\section{REFERENCES}

Caldeira RL, Jannotti-Passos LK, Lira PM, Carvalho OS 2004. Diagnostic of Biomphalaria snails and Schistosoma mansoni: DNA obtained from traces of shell organic materials. Mem Inst Oswaldo Cruz 99: 499-502.
Carvalho S, Caldeira RL, Simpson AJ, Vidigal TH 2001. Genetic variability and molecular identification of Brazilian Biomphalaria species (Mollusca: Planorbidae). Parasitology 123 (Suppl.): 197-209.

Corrêa LR, Paraense WL 1971. Susceptibility of Biomphalaria amazonica to infection with two strains of Schistosoma mansoni. Rev Inst Med Trop Sao Paulo 13: 387-390.

Paraense WL 1966. Biomphalaria amazonica and B. cousini, two new species of neotropical planorbid molluscs. Rev Bras Biol 26: 115-126.

Paraense WL, Corrêa LR 1973. Susceptibility of Biomphalaria peregrina from Brazil and Ecuador to two strains of Schistosoma mansoni. Rev Inst Med Trop Sao Paulo 15: 127-130.

Vidigal THDA, Caldeira RL, Simpson AJG, Carvalho OS 2000a. Further studies on the molecular systematics of Biomphalaria snails from Brazil. Mem Inst Oswaldo Cruz 95: 57-66.

Vidigal THDA, Kissinger JC, Caldeira RL, Pires EC, Monteiro E, Simpson AJ, Carvalho OS 2000b. Phylogenetic relationships among Brazilian Biomphalaria species (Mollusca: Planorbidae) based upon analysis of ribosomal ITS2 sequences. Parasitology 121: $611-620$. 